\title{
Managing depression in primary care: it's not only what you do it's the way that you do it
}

Common mental health problems place significant demands on primary care services both in terms of time and resources. ${ }^{1,2}$ Of the common mental health problems, depression and anxiety make up about $97 \% .^{3}$ Depression is costly to the individual, their family and community, and represents a significant loss of human capital. It poses a considerable burden to the national economy ${ }^{4}$ and people with depression represent the largest single group receiving incapacity benefits. ${ }^{5,6}$ Depression is often chronic, has high relapse rates, increases the likelihood of suicide, and is associated with an increased risk of many physical disorders. ${ }^{7}$ It continues to present a major public health challenge ${ }^{8}$ despite public education campaigns and evidence-based treatment. ${ }^{9,10}$

Four papers in this month's BJGP highlight some of the potential problems of treating patients with depression. Patients frequently do not take antidepressant medication as prescribed with as few as $10 \%$ of patients completing a course of treatment. ${ }^{11}$ Van Geffen et al, in this issue of the BJGP, explore the rates of commencing treatment in patients prescribed antidepressants. ${ }^{12}$ They found that $28 \%$ of people newly prescribed an antidepressant by their GP never cashed in their prescriptions or only did so on one occasion. This failure to take the prescribed antidepressants was higher in people given antidepressants for nonspecific indications, such as sleep problems, fatigue, relationship problems, and in non-Western immigrants and older people. This compares to drop-out rates for psychological therapies of about $30 \%{ }^{7}$ and poses a particular challenge for healthcare professionals.

Antidepressant prescribing has risen in many countries over recent years. Morrison et al, in this issue of the journal, surveyed antidepressant prescribing in Scotland, and found wide prescribing variations. ${ }^{13}$ These variations showed a positive association with morbidity levels, and lower rates of prescribing were associated with better availability of psychological therapy and a higher proportion of ethnic minorities on the practice lists. Interestingly, none of the quality indicators that they used was associated with prescribing levels.

Neither of these studies link prescribing to diagnosis or outcomes and it is not possible to make judgements on the appropriateness or quality of the prescribing. Nevertheless, they do suggest that prescribing for specific problems encourages adherence and that, in general, prescribing levels probably reflect levels of morbidity in the population. This is reinforced by a similar study of antidepressant prescribing in England $^{14}$ which also found positive correlations between volumes of antidepressant prescribed, deprivation, and levels of chronic illness, but negative correlations with the proportion of people from black ethnic groups in the population. No association between quality indicators and prescribing was found in this study either.

The lack of correlation with quality factors may not be surprising given the uncertainty about the validity of these indicators in relation to the standards of consultation for psychological episodes. Also in this issue is Vedavanam et al's preliminary study of the prevalence of quality indicators for depression management in primary care. ${ }^{15}$ Results suggest that GPs may be offering antidepressants to those that they identify as being depressed and giving appropriate follow-up to those for whom they prescribed antidepressants, but that asking about current medication, suicide, and substance misuse in the consultation was less likely. Other studies suggest a cautious approach to antidepressant prescribing, with GPs often prescribing antidepressants to more symptomatic patients. ${ }^{16,17}$

The fourth paper in this issue by Cuijpers et al is a meta-analysis of randomised controlled trials of structured psychological therapies. ${ }^{18}$ What is most surprising about this meta-analysis is the small adjusted effect size of psychological therapies (standardised mean difference 0.2; number needed to treat [NNT] 5.75). This may be explained partly by the heterogeneous group of therapies included in the analyses and the heterogeneity of the samples under study. However, even when these factors are taken into consideration, their results are disappointing. Their analysis confirms the results of previous studies that suggest psychological therapies are probably as effective as antidepressant treatment. A meta-analysis of antidepressant treatment in primary care $^{19}$ found an NNT for selective serotonin reuptake inhibitors of around 6.0.

Also of interest is that Cuijpers et al found no effect in studies that had recruited by screening for depression as opposed to those studies that relied on referral by a GP. This has significant implications, especially when GPs are being encouraged to case-find depression in high-risk groups. Previous research has suggested that case-finding does not alter GP practice, ${ }^{20}$ and Cuijpers et al's research suggests there may be very good patientlevel reasons to explain this. Others have advised that screening/case-finding for depression is only likely to be useful where integrated systems of care are in place to ensure that those who screen positive have access to the appropriate resources. ${ }^{21}$

The findings from the four studies in this issue add to a growing body of evidence suggesting that even in the rarefied world of research, depression outcomes are far from optimal. This is probably best demonstrated in the Sequenced Treatment Alternatives to Alleviate Depression $\left(S T_{A}{ }^{*} \mathrm{D}\right)$ report, ${ }^{22}$ a large study (funded to the tune of US\$35 million) that aimed to determine what treatments are most likely to result in remission from depression. Designed to mimic clinical 
practice, it enrolled over 4000 people with major depression and began treating them with one antidepressant (citalopram) before progressing those, who did not remit at this first step, to other antidepressants or cognitive therapy singly or in combination, over a series of four steps. The results were sobering: only $30 \%$ of patients achieved remission after initial treatment with a selective serotonin reuptake inhibitor. In those that failed to remit, switching to another antidepressant or having their antidepressant augmented resulted only in a further $30 \%$ achieving remission. Even under randomisedcontrolled-trial conditions, drop-out rates were high with $21 \%$ dropping out after step 1 and $30 \%$ dropping out after step 2 . At step 3 only $14 \%$ remitted and at step 4 , $13 \%$. Thus, the more treatments required the less likely you are to achieve remission. They also found that the more treatments you require the higher the likelihood of relapse. Clinicians will be familiar with these rates of remission in their day-to-day practice and also perhaps with similar response rates to the structured psychological therapies.

So, should we succumb to therapeutic nihilism or can depression care be optimised to ensure maximum efficacy? The good news from the $\operatorname{STAR}^{\star} \mathrm{D}$ study is that following all the four steps in sequence resulted in a cumulative remission rate of around $70 \%$ (in those who take the treatments and across primary and secondary care). The challenge for both primary and secondary care is how to ensure patients are stepped up appropriately if people fail to achieve remission on a particular treatment. Part of the solution to this may be to increase capacity. One of the problems of managing treatment of depression in primary care (and secondary care) has been the high level of unmet need for psychological therapy, ${ }^{23,24}$ awareness of which has resulted in calls for an improvement in access to psychological treatments for people with common mental health problems. ${ }^{25}$ More than 10000 new therapists are estimated to be required to deliver these therapies. ${ }^{25,26}$

In response, the Department of Health in England developed the 'Improving Access to Psychological Therapies' (IAPT) pilots, which are now being extended ${ }^{27}$ with the training of 3600 new therapists over the next 3 years. These IAPT schemes will use a stepped-care approach offering both low- and high-intensity therapies. The high-intensity approaches will use cognitive behavioural therapy (CBT) of up to 16 sessions. The low intensity approaches may include computerised CBT, guided self-help, problem solving, behavioural activation, brief CBT, and medication management.

This new investment is welcomed, but the increase of personnel on its own may be insufficient without new structural arrangements to ensure the delivery of effective care. Evidence suggests that collaborative models of care may be most effective here, ${ }^{28,29}$ using (1) a multiprofessional approach to patient care involving GP, mental health specialists, and a case manager (a professional or paraprofessional providing regular contacts with the patient about medication or psychosocial support); (2) a structured patient management plan with both brief psychological therapy and medication management where appropriate; and (3) scheduled patient follow-ups with systematic routine data collection to inform supervision and decision making about treatment plans. This would provide an integrated coherent model of care necessary, for instance, if case-finding is to be optimally effective.

The benefits of cohesive collaborative care approaches suggest that the way in which treatment is delivered is as important as the treatment itself. There are similar benefits to be accrued from the way the physician approaches the consultation with the patient with depression and negotiation of any treatments, including the prescribing of antidepressants.

Given the limited effect sizes of available treatments and the need to try multiple approaches in many instances, Balint's idea of 'the Doctor is the Drug' needs to be enhanced (and broadened to include the whole health care team). There is a large literature on the biopsychosocial approach to medicine and this has been advocated for the assessment and management of people with depressive symptoms. ${ }^{30}$
It is important for the patient and physician to develop shared understanding about diagnosis and treatment, maintained through the development of a trusting relationship and an open exchange of evidence and ideas. ${ }^{31}$ Recent studies have described the negative effects of leaving patients' agendas unvoiced. ${ }^{32}$ Sharing decisions about treatment, if the patient wishes, can follow the development of this relationship.

Also of relevance here are ideas taken from another body of literature, that of recovery, which have developed from the narratives of people with long-term mental health problems. ${ }^{33,34}$ In the sense used here, recovery is concerned with 'social recovery', the idea of building a life beyond illness, of recovering one's life: an important outcome and common to people with other chronic illnesses, such as diabetes, asthma, and arthritis. Central to recovery is the development of a sense of personal control (agency) and the sustaining of motivation and supporting expectations of an individually fulfilled life (hope).

The physician may facilitate this through the development of a trusting relationship, based on partnership with the patient, a shared understanding about diagnosis and risk, understanding the patients' concerns and expectations, listening to narrative, agreeing on a plan of action, sharing information about treatments, and during follow-up assessing progress, symptoms, risk, and treatment, discussing new concerns, and deciding about ongoing management. As with chronic disease management, selfmanagement and self-determination, rather than professionally-dominated strategies are central.

The use of evidence-based treatments are essential for improving the management of depression in primary care, but these alone are probably insufficient. To enhance the limits of these approaches it appears that integrative coherent systems of care that incorporate close collaboration with mental health specialists and nonstatutory services, case management, and a recognition and acknowledgment of the importance of the healthcare professional-patient relationship are vital. It 
seems that it is not only what you do, but the way that you do it that matters.

\section{Jed Boardman,}

Senior Lecturer in Social Psychiatry, Institute of Psychiatry, Kings College London.

\section{Paul Walters,}

Research Fellow \& Specialist Psychiatrist, Institute of Psychiatry, Kings College London.

\section{REFERENCES}

1. Goldberg D, Huxley P. Common mental disorders: a biosocial model. London: Tavistock/Routledge, 1992.

2. Ustun TB, Sartorius N (eds). Mental illness in general health care. Chichester: Wiley, 1995.

3. Richards D, Suckling R. Improving access to psychological therapy: the Doncaster demonstration site organisational model. Clinical Psychology Forum 2008; 181: 9-16.

4. Sainsbury Centre for Mental Health. Money for mental health. A review of public spending on mental health care. London: Sainsbury Centre for Mental Health, 2003.

5. Sainsbury Centre for Mental Health. Mental health and employment. Briefing No. 33. London: Sainsbury Centre for Mental Health, 2007.

6. HM Government. Department for Work and Pensions five year strategy. Opportunity and security throughout life. CM 6447. London: The Stationary Office, 2005

7. Scott J. Depression should be managed like a chronic disease. BMJ 2006; 332: 985-986.

8. Weich S. Prevention of the common mental health disorders: a public health perspective. Psychol Med 1997; 27: 757-764.

9. Andrews G. Why does the burden of disease persist? Relating the burden of anxiety and depression to the effectiveness of treatment. Bull World Health Organ 2000; 78: 446-454.

10. National Institute for Clinical Excellence. Depression (amended): Management of depression in primary and secondary care. NICE clinical guideline 23. London: National Institute for Clinical Excellence, 2007.

11. Lepine JP, Gastpar M, Mendlewicz J, et al. Depression in the community: the first pan-European study DEPRES (Depression Research in European Society). Int Clin Psychopharmacol 1997; 12: 19-29.

12. Van Geffen ECG, Gardarsdottir H, van Hulten R, et al. Initiation of antidepressant therapy: do patients follow the GP's prescription? Br I Gen Pract 2009; 59: $81-87$

13. Morrison J, Anderson MJ, Sutton M, et al. Factors influencing variation in prescribing of antidepressants by general practices in Scotland. $\mathrm{Br}$ Gen Pract 2009; 59: 88-93.

14. Walters P, Ashworth M, Tylee A. Ethnic density, physical illness, social deprivation and antidepressant prescribing in primary care: ecological study. $\mathrm{Br} \mathrm{J}$ Psychiatry 2008; 193: 235-239.

15. Vedavanam S, Steel N, Broadbent J, et al. Recorded quality of care for depression in general practice: an observational study. Br J Gen Pract 2009; 59: 94-98.

16. Hyde J, Calnan M, Prior L, et al. A qualitative study exploring how GPs decide to prescribe antidepressants. Br J Gen Pract 2005; 55: 755-762.

17. Hyde J, Evans J, Sharp D, et al. Deciding who gets treatment for depression and anxiety: a study of consecutive GP attenders. Br I Gen Pract 2005; 55: 846-853.

18. Cuijpers P, van Straten A, van Schaik A, Andersson G. Psychological treatment of depression in primary care: a meta-analysis. Br J Gen Pract 2009; 59: 120-127.

19. Arroll B, MacGillivray S, Ogston S, et al. Efficacy and tolerability of tricyclic antidepressants and SSRIs compared with placebo for treatment of depression in primary care: a meta-analysis. Ann Fam Med 2005: 3(5): 449-445.

20. Dowrick C, Buchan I. Twelve month outcome of depression in general practice: does detection or disclosure make a difference? BMJ 1995; 311: 1274-1276.

21. Pignone MP, Gaynes BN, Rushton JL, et al. Screening for depression in adults: a summary of the evidence for the U.S. Preventive Services Task Force. Ann Intern Med 2002; 136: 765-776.

22. Rush AJ, Trivedi MH, Wisniewski SR, et al. Acute and longer-term outcomes in depressed outpatients requiring one or several treatment steps: a STAR ${ }^{\star} \mathrm{D}$ report. Am J Psychiatry 2006; 163: 1905-1017.

23. Boardman J, Willmott S, Henshaw C. The prevalence of the needs for mental health treatment in general practice attenders. Br J Psychiatry 2004; 185: 318-327.

24. Bebbington P, Marsden L, Brewin CP. The need for psychiatric disorder in the general population: the Camberwell Needs for Care Survey. Psychol Med 1997; 27: 821-834.

25. Layard R. The case for psychological treatment centres. BMJ 2006; 332: 1030-1032.
26. Boardman J, Parsonage M. Delivering the government's mental health policies: services, staffing and costs. London: The Sainsbury Centre for Mental Health, 2007.

27. Department of Health. Improving access to psychological therapies implementation plan: national guidelines for regional delivery. London: Department of Health, 2008.

28. Gilbody S, Bower P, Fletcher J, et al. Collaborative care for depression: a systematic review and cumulative meta-analysis. Arch Intern Med 2006; 166: 2314-2321.

29. Richards DA, Lovell K, Gilbody S, et al. Collaborative care for depression in UK primary care: a randomised controlled trial. Psychol Med 2008; 38 279-287.

30. Dowrick CF. Beyond depression: a new approach to understanding and management. Oxford: Oxford University Press, 2004.

31. Royal Pharmaceutical Society of Great Britain. From compliance to concordance: towards shared goals in medicine taking. London, RPS, 1997.

32. Barry CA, Bradley CP, Britten N, et al. Patients' unvoiced agendas in general practice consultations: qualitative study. BMJ 2005; 320: 1246-1250.

33. Royal College of Psychiatrists/SCIE/CSIP. A common purpose: recovery in future mental health services. London: Social Care Institute for Excellence, 2007 http://www.scie.org.uk (accessed 13 Dec 2008).

34. Shepherd G, Boardman J, Slade M. Making recovery a reality. London: Sainsbury Centre for Mental Health, 2008 .

DOI: 10.3399/bjgp09X395049

\section{ADDRESS FOR CORRESPONDENCE}

\section{Jed Boardman}

Section of Social Psychiatry, Health

Service and Population Research

Department, Box 033, David Goldberg

Centre, Institute of Psychiatry, De

Crespigny Park, London SE5 8AF.

E-mail: Jed.Boardman@slam.nhs.uk 